\title{
Rancang Bangun Aplikasi Pembelajaran Bahasa Arab Untuk Siswa Madrasah Ibtidaiyah Berbasis Android
}

\author{
Waeisul Bismi ${ }^{1}$, Musriatun Napiah² ${ }^{2}$ Jordy Lasmana Putra ${ }^{3}$, Fajar Shidiq ${ }^{4}$ \\ ${ }^{1}$ Program Studi Ilmu Komputer, Fakultas Teknik dan Informatika Universitas Bina Sarana Informatika \\ Jl. Kramat Raya No.98, Jakarta Pusat, DKI Jakarta 10450, Indonesia. \\ ${ }^{2}$ Program Studi Teknologi Komputer, Fakultas Teknik dan Informatika Universitas Bina Sarana Informatika \\ Jl. Kramat Raya No.98, Jakarta Pusat, DKI Jakarta 10450, Indonesia. \\ ${ }^{3}$ Program Studi Teknik Informatika, Fakultas Teknologi Informasi, Uiversitas Nusa Mandiri \\ Jl. Jatiwaringin No. 2, Cipinang Melayu, Makasar, Jakarta Timur - 13620, Indonesia. \\ ${ }^{4}$ Program Studi Hubungan Masyarakat, Fakultas Komunikasi dan Bahasa Universitas Bina Sarana Informatika \\ Jl. Kramat Raya No.98, Jakarta Pusat, DKI Jakarta 10450, Indonesia.
}

e-mail: $\underline{1}$ Waeisul.wbn@bsi.ac.id, ${ }^{2}$ Musriatun.mph@bsi.ac.id, ${ }^{3}$ Jordy.jlp@ nusamandiri.ac.id, ${ }^{4}$ Fajar.fsq@bsi.ac.id

Artikel Info : Diterima : 22-02-2021 | Direvisi : 15-06-2021 | Disetujui : 19-07-2021

\begin{abstract}
Abstrak - Dengan semakin terbukanya pola pikir masyarakat sekarang khususnya Indonesia membuat kita mudah menerima sesuatu hal baru dan mengimplementasikannya dalam kehidupan kita, hal baru tersebut banyak mucul dalam berbagai aspek seperti salah satunya adalah pendidikan. Dalam hal pendidikan baiknya dilakukan di usia sedini mungkin terutama dalam hal pembelajaran bahasa asing kedua atau bahasa asing pengganti bahasa inggris, hal inilah yang disadari oleh pihak guru Madrasah Ibtidaiyah dan mulai diterapkan belakangan ini, untuk melakukan hal ini Madrasah Ibtidaiyah membutuhkan alat bantu untuk membuat metode pembelajaran ini menjadi efektif. Oleh sebab itu penulis membuat sebuah aplikasi pembelajaran mengenai kosa kata bahasa arab yang akan mempermudah guru madrasah ibitdaiyah untuk memperkenalkan secara efektif tentang bahasa arab dasar seperti pengenalan nama - nama hari untuk anak-anak Madrasah Ibtidaiyah yang dilengkapi dengan suara dan gambar yang bisa menarik minat anak-anak. Aplikasi pembelajaran ini dapat digunakan pada smartphone Android dengan minimal OS Android 5.0 (Lollipop) dan maksimal OS Android adalah 8.1 (Oreo).
\end{abstract}

Kata Kunci : Aplikasi Android, Pembelajaran Bahasa Arab, Madrasah Ibtidaiyah

\begin{abstract}
With the increasingly open mindset of society today, especially Indonesia, it makes it easy for us to accept new things and implement them in our lives, these new things appear in many aspects such as one of which is education. In terms of education, it is better if it is carried out at an early age, especially in terms of learning a second foreign language or a foreign language substituting for English, this is what elementary school teachers have realized and has begun to be implemented recently, to do this elementary schools need tools to create methods. this learning becomes effective. Therefore the authors make an Arabic learning application that will make it easier for elementary school teachers to effectively introduce basic Arabic such as the recognition of the names of the day for elementary school children, which is equipped with sounds and images that can attract children's interests. This application can be run on an Android smartphone with a minimum Android OS 5.0 (Lollipop) and a maximum Android OS is 8.1 (Oreo).
\end{abstract}

Keywords : Android Application, Arabic Learning, Elementary School

\section{PENDAHULUAN}

Pada zaman sekarang dimana teknologi sudah semakin maju, perkembangan teknologi dan informasi pada saat ini sangat begitu pesat, dan dapat menjadikan kita tidak bisa terpisahkan dengan perkembangannya (Rahmawati \& Abdurahman, 2019). Banyak bermunculan invovasi-inovasi terbaru dalam berbagai aspek bidang, salah satunya di bidang teknologi mobile. Hingga saat ini teknologi mobile sudah memiliki perkembangan yang pesat sebagai akibatnya memiliki beraneka ragam kegunaan yang selalu dimanfaatkan oleh banyak orang buat keperluan nan berarti dibeberapa bidang anatara lain seperti bidang kcesehatan, hiburan, transaksi, juga dalam bidang edukasi (Bismi et al., 2020). Teknologi mobile dapat menyamai teknologi komputer, dalam sektor

131

This work is licensed under a Creative Commons Attribution-ShareAlike 4.0 International License. 
hardware sebuah kamera dan teknologi untuk smartphone saat ini sudah bisa menjalankan Virtual Reality dan Augmented Reality lalu di sektor software juga sudah bermunculan banyak inovasi-inovasi seperti halnya kecerdasan buatan atau artificial intelligence (AI) yang dapat menghubungkan berbagai perangkat hanya dengan menggunakan smartphone tetapi di sektor Operating system (OS) atau sistem operasi untuk smartphone tidak banyak berubah seperti operasi sistem yang dimiliki oleh Apple yakni iOS dan Android milik Google. Tetapi dengan berbagai customisasi pada user interface dan user experience.

Dan dari kedua sistem operasi tersebut, Android lah yang memiliki pengguna terbanyak di Indonesia. Dengan demikian tidak dapat dipungkiri bahwa pengguna terbanyak di seluruh dunia. Android memiliki berbagai macam aplikasi yang disediakan oleh pihak Google selaku pemilik Android ataupun oleh pihak ketiga. Dikarenakan sistem operasi pada perangkat Android merupakan sebuah sistem operasi yang menjalankan open source, jadi siapa saja bisa menjadi developer atau pengembang aplikasi di dalamnya. pemanfaatan teknologi yang baik akan sangat membantu untuk memberikan pembelajaran kepada anak-anak. Teknologi yang dirancang dan dikonsep sedemikian rupa akan sangat menarik minat anak-anak untuk menggunakannya (Aditama et al., 2018).

Penggunaan teknologi dan media pembelajaran pada zaman sekarang sangatlah diperlukan dalam upaya peningkatan kualitas pembelajaran. Media pembelajaran adalah alat yang dipergunakan dalam memberikan suatu materi pembelajaran,antara lain seperti buku, kitab, rekaman suara, video pembelajaran, komputer ataupun sebuah aplikasi yang menghasilkan gambar dan suara seperti televisi (Septian et al., 2018). Penerapan teknologi serta media pada pembelajaran bisa menghasilkan suasana belajar yang nyaman, dimana para siswa bisa ikut andil belajar secara aktif. Media pembelajaran adalah penghubung keduanya atara para pengajar dan juga para murid, berkat manfaar mediapembelajaran ini para muird tak akan merasa lagi dibatasi oleh batas-batas ruang dan juga waktu didalam kelas, karena para murid dapat belajar kapanpun dan dimanapun dalam berbagai tempat.

Aplikasi pembelajaran Bahasa Arab merupakan salah satu pendekatan dalam sistem belajar, apalagi di Negara yang memiliki penduduk beragama muslim terbanyak di dunia. Sehingga Bahasa Arab banyak diminati dan pada zaman ini tidak hanya Bahasa Inggris saja yang kita pelajari tetapi juga Bahasa Asing ketiga sebagai Bahasa pendukung. Maka dari itu penulis membuat aplikasi pembelajaran Bahasa Arab agar memudahkan dalam belajar Bahasa Arab untuk siswa Madrasah Ibtidaiyah serta sebagai solusi bagi siswa dalam melakukan kegiatan belajar supaya semangat dan tidak merasa bosan, dan juga siswa dapat memahami kemajuan teknologi yang sekarang yang sedang berkembang pesat (Kurniawan \& Katarina, 2021).

\section{METODE PENELITIAN}

Metode yang digunakan dalam penelitian ini yaitu metode SDLC. Model SDLC air terjun (waterfall) merupakan model yang memiliki istilah lain yakni model linear yang berurutan (sequential linear) atau alur hidup klasik (classic life style) dikarenakan model ini memiliki serta menyediakan metode yang menerapakan pendekatan pada alur hidup di perangkat lunak secara terurut. (Salahudin, 2021).

1. Teknik Pengumpulan Data

Didalam Pembuatan aplikasi pembelajaran Bahasa arab ini penulis menerpakan beberapa tekni dalam pengumpulan data, diantaranya yaitu sebagai berikut.

a. Pengamatan (Observation)

Pengamatan yang penulis lakukan adalah dengan mengamati lingkungan Madrasah Ibtidaiyah dan

kebiasaan siswa-siswa dalam menggunakan aplikasi pada gadget mereka.

b. Studi Literatur

Selain melakukan pengamatan, Penulis juga melakukan studi pustaka dengan mempelajari buku serta

artikel artikel yang ada di internet. Dari bahan-bahan tersebut diambil teori-teori yang dapat dijadikan

landasan guna menunjang pembuatan aplikasi.

c. Uji Coba dan Evaluasi

Pada tahap ini peneliti melakukan uji coba program pada virtual Android device dan juga pada Android device serta melakukan evaluasi hasil dari pembuatan aplikasi yang penulis lakukan.

\section{Teknik Perancangan}

Agar mendapatkan hasil yang sempurna serta efektif pada teknik perancangan ini, peneliti membuat langkah - langkah pengembangan aplikasi pembelajaran bahasa arab dengan menerapkan model SDLC dan berikut penjelasannya :

a. Analisa dan pengumpulan data

Tahapan ini peneliti mencari informasi kebutuhan dari penerbit dan pembaca terkait materi - materi bahasa arab untuk kalangan siswa Madrasah Ibtidaiyah sehingga menciptakan efisiensi dan keefektifan dari aplikasi tersebut. 
b. Perancangan sistem

Dalam Tahapan perancangan sistem, peneliti menggunakan beberapa software seperti Adobe Photoshop, dan PicArt guna untuk menghasilkan tampilan interface serta alur pada aplikasi pembelajaran Bahasa arab ini yang menarik dan edukatif.

c. Pembuatan aplikasi

Software yang digunajan dalam tahapan pembuatan aplikasi menggunkan editor Android Studio versi 4.1.1 yang juga menerapkan kode bahasa pemrograman Java dan menghasilkan aplikasi ber-platfrom Android.

d. Implementasi sistem

Implementasi akan dicoba oleh beberapa siswa di Madrasah Ibtidaiyah.

e. Penyusunan laporan

Di tahap ini peneliti membuat penyusunan serta penulisan laporan sebagai dokumentasi terhadap penelitian yang telah dilakukan.

3. Kajian Pustaka

Kajian pustaka yang digunakan untuk bahan landasan dalam pembuatan aplikasi pembelajaran bahasa arab untuk siswa Madrasah Ibtidaiyah :

1. Aplikasi

Aplikasi biasanya dibuat untuk mempermudah orang-orang mengerjakan pekerjaan maupun sebagai kebutuhan manusia pada beraneka ragam manfaatnya seperti dalam hal aspek Kesehatan, transaksi, bisni, hiburan, transportasi maupun dalam bidang edukasi (Bismi et al., 2020).

2. Android Studio

Menurut (Supardi, 2017) dalam penelitiannya isitilah Android adalah suatu Operating system pada perangkat smartphone yang berbasis linux serta mencakup perihal middleware, sedangkan menurut (Firly, 2018) pada penelitiannya Android Studio adalah suatu lingkungan dalam pengembangan yakni Integrated development environment (IDE) yang terintegrasi resmi dan dirancang khusus bagi para pengembang aplikasi yang menggunakan system google. Bisa juga dibilang bahwa Android Studio merupakan pengganti dari Eclipse Android Development Tools atau ADT sebagai IDE utama dalam pengembangan aplikasi Android yang asli dan tentunya Android merupakan platform open source yang bebas untuk dikembangkan oleh siapapun.

3. Android Virtual Device (AVD)

Android Virtual Devices adalah emulator aplikasi komputer yang meniru cara kerja perangkat Android sesungguhnya. Hampir sebagian besar fitur-fitur yang ada di perangkat Android dapat ditemukan pada AVD, kecuali beberapa fitur yang membutuhkan aksesdengan hardware tertentu seperti GPS,kamera dan sensor. Dengan menggunakan emulator pada AVD pengujian dapat dilakuakn terhadap suatu aplikasi yang dibuat oleh para pengembang aplikasi dengan cepat dan juga mudah dengan melakukan proses debugging tanpa harus menggunakan perangkat keras smartphone berbasis Android (Juhara, 2016).

4. Android Software Development Kit (SDK)

Android SDK (Software Development Kit) merupakan suatu alat bantu yang sangat diperlukan dalam pembuatan aplikasi yang memiliki isitilah lain tools API (Application Programming Interface) dan API ini mengunakan Bahasa pemrograman berbasis java yang berguna untuk mengembangkan aplikasi yang dibuat yang diperlukan sebagai alat bantu dan API untuk mulai mengembangkan aplikasi pada platform Android menggunakan bahasa pemrograman Java (Kusniyati \& Pangondian Sitanggang, 2016).

5. Java Development Kit (JDK)

Java Development Kit adalah sebuah produk yang dikembangkan oleh Oracle yang berguna saat kita menulis kode program seperti halnya JRE (Java Runtime Environment), JDK juga mempunyai JVM (Java Virtual Manchine) di dalamnya. JDK terdiri dari lingkungan eksekusi program yang berada di atas Operating System, sebagaimana dibutuhkan oleh para programmer untuk mengcompile, membenahi bugs yang ada dan menjalankan tambahan-tambahan dari program intinya yang ditulis dengan menggunakan bahasa pemrograman Java (Ramadhan M, 2018) dan JDK sebagai alat bantu untuk menerjemahkan kode atau kompilasi program agar menjadi aplikasi berbasis java (Dharmawan et al., 2017). 
6. Extensible Markup Language (XML)

Pada tahun 1996 Extensible Markup Language (XML) mulai dikembangkan dan pada tahun 1998 bulan februari telah mendapatkan pengakuan dari W3C. XML merupakan teknologi turunan dari hasil $S G M L$ yang dikembangkan pada awal tahun 80 -an yang sudah banyak dipergunakan dalam teknis dokumentasi di berbagai proyek berskala besar, Markup language adalah Sistem modern untuk menganotasi dokumen dengan cara yang secara sintaksis dibedakan dari teks (Dharmawan et al., 2017).

7. Flowchart

Flowchart adalah representasi secara simbolik dari suatu algoritma atau prosedur untuk menyelesaikan suatu masalah, dengan menggunakan Flowchart akan memudahkan pengguna melakukan pengecekan bagian-bagian yang terlupakan dalam analisis masalah, disamping itu Flowchart juga berguna sebagai fasilitas untuk berkomunikasi antara pemrogram yang bekerja dalam tim suatu proyek (Santoso \& Nurmalina, 2017).

8. HIPO

HIPO (Hierarchy plus Input-Process-Output) merupakan teknologi yang dikembangkan serta didukung oleh IBM yakni sebuah teknik yang digunakan sebagai alat desain dan mendokumentasikan system program yang dibentuk dengan menekankan pada fungsi-fungsi system yang akan mempercepat prosedur dalam suatu system. HIPO berbasis kepada fungsi, yaitu setiap modul dalam sistem digambarkan oleh fungsi utamanya (Putra \& Agustaf, 2019).

\section{HASIL DAN PEMBAHASAN}

Aplikasi pembelajaran bahasa arab merupakan aplikasi yang dibuat dengan software Android Studio dengan menggunakan bahasa pemrograman java. Aplikasi ini berfungsi untuk mempermudah dalam memahami dan menghafal nama hari, bulan, warna, dan benda khususnya untuk anak-anak sekolah dasar karena tampilan (user interface) yang menarik disertai dengan audio dubber untuk memudahkan dalam mengahafal.

Didalam aplikasi ini terdapat materi dan soal latihan yang isi soalnya sudah dipelajari sebelumnya serta evaluasi nilai hasil dari latihan soalnya. Sehingga nantinya program ini dapat menumbuhkan minat belajar anakanak sekolah dasar dan dapat membuat minat akan pengetahuan bahasa baru berkembang di Indonesia.

\section{Analisa dan Pengumpulan Data}

Analisa kebutuhan aplikasi dalam pembuatan aplikasi pembelajaran bahasa arab, meliputi 2 (dua) aspek diantaranya yaitu :

1. Hardware

Perangkat keras (hardware) merupakan suatu sistem komputer yang terdiri dari seluruh komponen yang memungkinkan komputer dapat melaksanakan tugasnya dengan baik. Dalam pembuatan aplikasi pembelajaran ini penulis menggunakan beberapa perangkat keras diantaranya sebagai berikut.

Tabel 1. Spesifikasi Laptop

\begin{tabular}{ccc}
\hline No & Nama Hardware & Keterangan \\
\hline 1 & Laptop & Lenovo thinkPad T450 \\
2 & Processor & Intel@ Core ${ }^{\mathrm{TM}}$ i5-5300U CPU @ 2.9GHz \\
3 & Memory & 4 GB \\
4 & VGA & Intel HD Graphics \\
5 & Hardisk & $500 \mathrm{~GB}$ \\
6 & Mouse & Logitch B170 \\
7 & Layar & 14 " HD + \\
\hline
\end{tabular}

Sumber: (Bismi et al., 2021)

Tabel 2. Spesifikasi Smartphone

\begin{tabular}{ccc}
\hline No & Nama Hardware & Keterangan \\
\hline 1 & Smartphone & Lenovo A600 \\
2 & Versi Android & 6.1 (Marshmellow) \\
3 & CPU & Snapdragon 410 Quad-core 1,2Ghz \\
4 & RAM & Gb \\
5 & Layar & $720 \times 1280$ pixels, 5,0 inches \\
\hline
\end{tabular}

Sumber: (Bismi et al., 2021) 


\section{Software}

Perangkat lunak adalah software atau aplikasi yang digunakan dalam proses pengimplementasian sistem atau aplikasi yang akan dibuat. Adapun perangkat lunak yang diperlukan oleh Aplikasi Pembelajaran Bahasa Arab berbasis Android antara lain :

Tabel 3. Spesifikasi Software

\begin{tabular}{c|c|c}
\hline No & Nama Hardware & Keterangan \\
\hline 1 & Sistem Operasi & Windows 10 Pro 64 bit \\
2 & Bahasa Pemrograman & Java \\
3 & IDE Android & Android Studio 4.1.1 \\
4 & Java Development Kit (JDK) & Versi 8u171 \\
5 & Android Software Development Kit (SDK) & API Level 22 \& 23 \\
6 & Android Driver & ADB Universal Driver \\
7 & Android OS & Marshmellow (6.0) \\
8 & Editor Gambar & Adobe PhotoShop Cs3 dan PicArt \\
\hline \multicolumn{2}{l}{ Sumber: (Bismi et al., 2021) }
\end{tabular}

\section{Perancangan Sistem}

Pada proses perancangan sistem penulis akan membahas tentang seputar Flowchart dan HIPO yang ada dalam aplikasi pembelajaran bahasa arab dan berikut penjelasanya :

1.Flowchart

Flowchart pada aplikasi pembelajaran bahasa arab ini terbagi menjadi 4 bagian yakni menu utama, menu belajar, menu bermain, dan pengaturan dan berikut penjabarannya:

a. Flowchart menu bermain

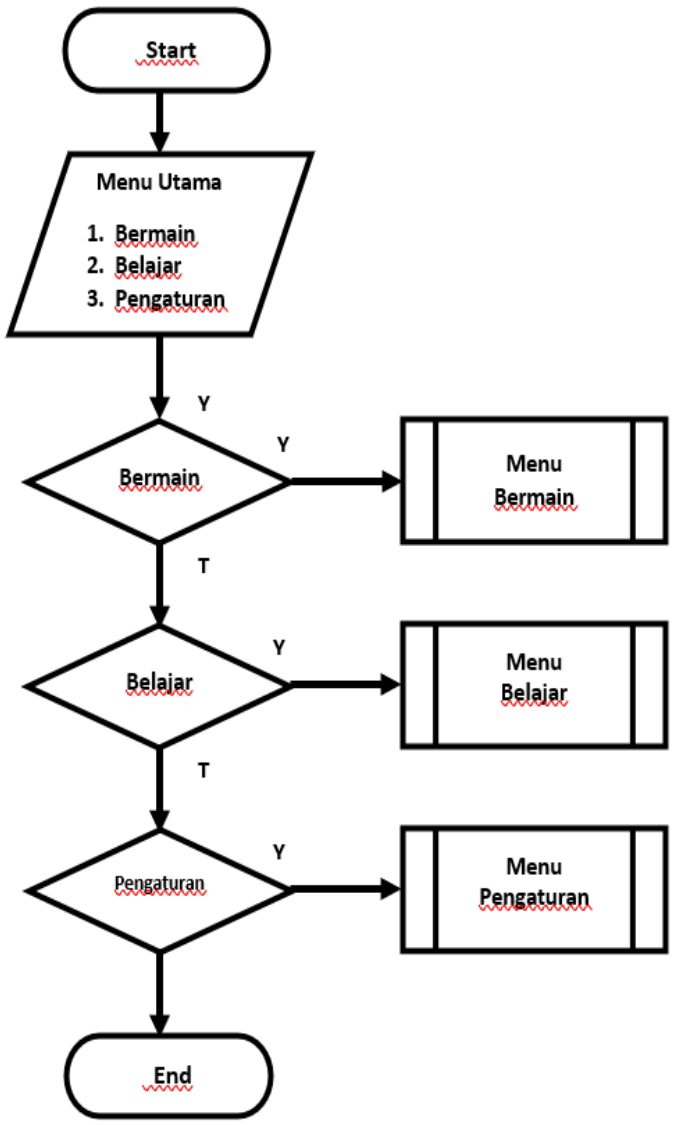

Sumber: (Bismi et al., 2021)

Gambar 1. Flowchart Menu Utama
b.Flowchart Menu Belajar

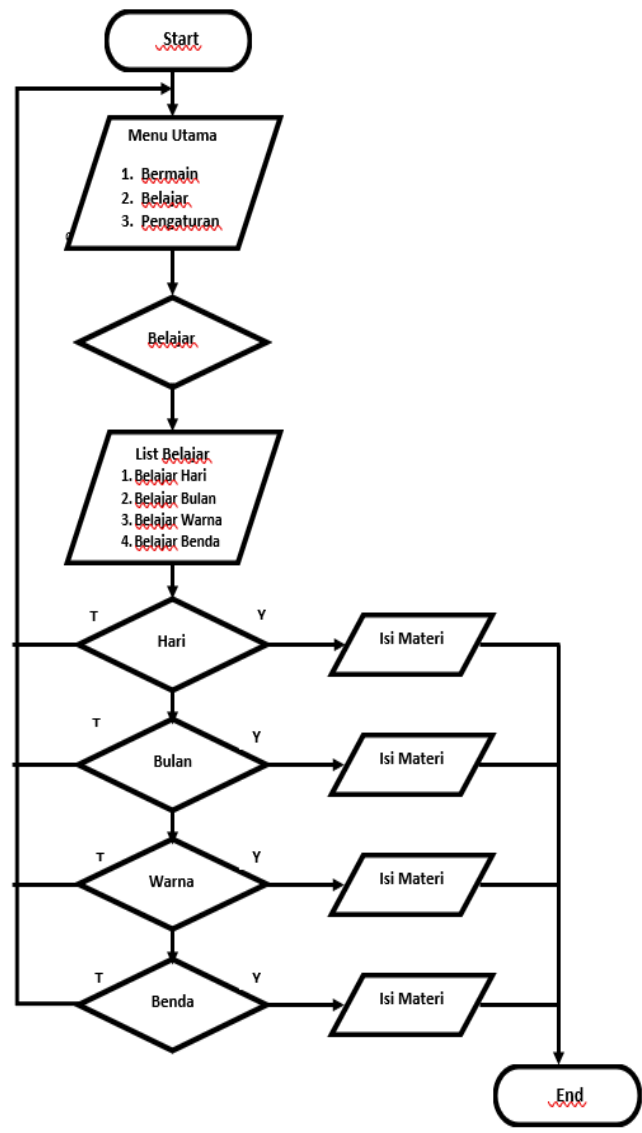

Sumber: (Bismi et al., 2021)

Gambar 2. Flowchart Menu Belajar 
c.Flowchart Menu Bermain

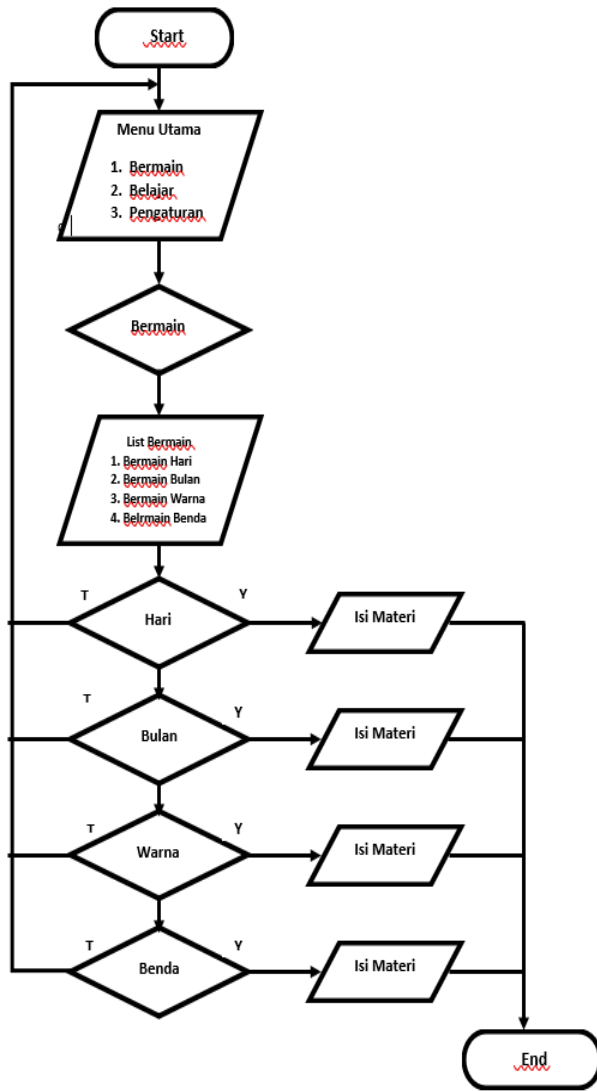

Sumber: (Bismi et al., 2021)

Gambar 3. Flowchart Menu Bermain
d.Flowchart Pengaturan

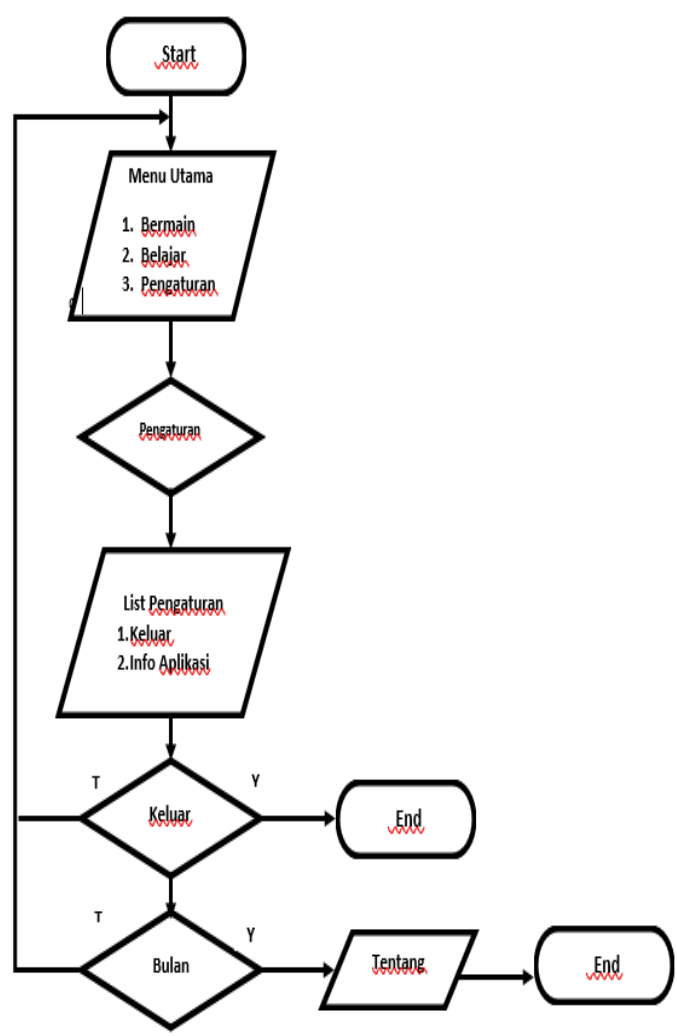

Sumber: (Bismi et al., 2021)

Gambar 4. Flowchart Menu Pengaturan

2. HIPO (Hierarchy plus Input-Process-Output)

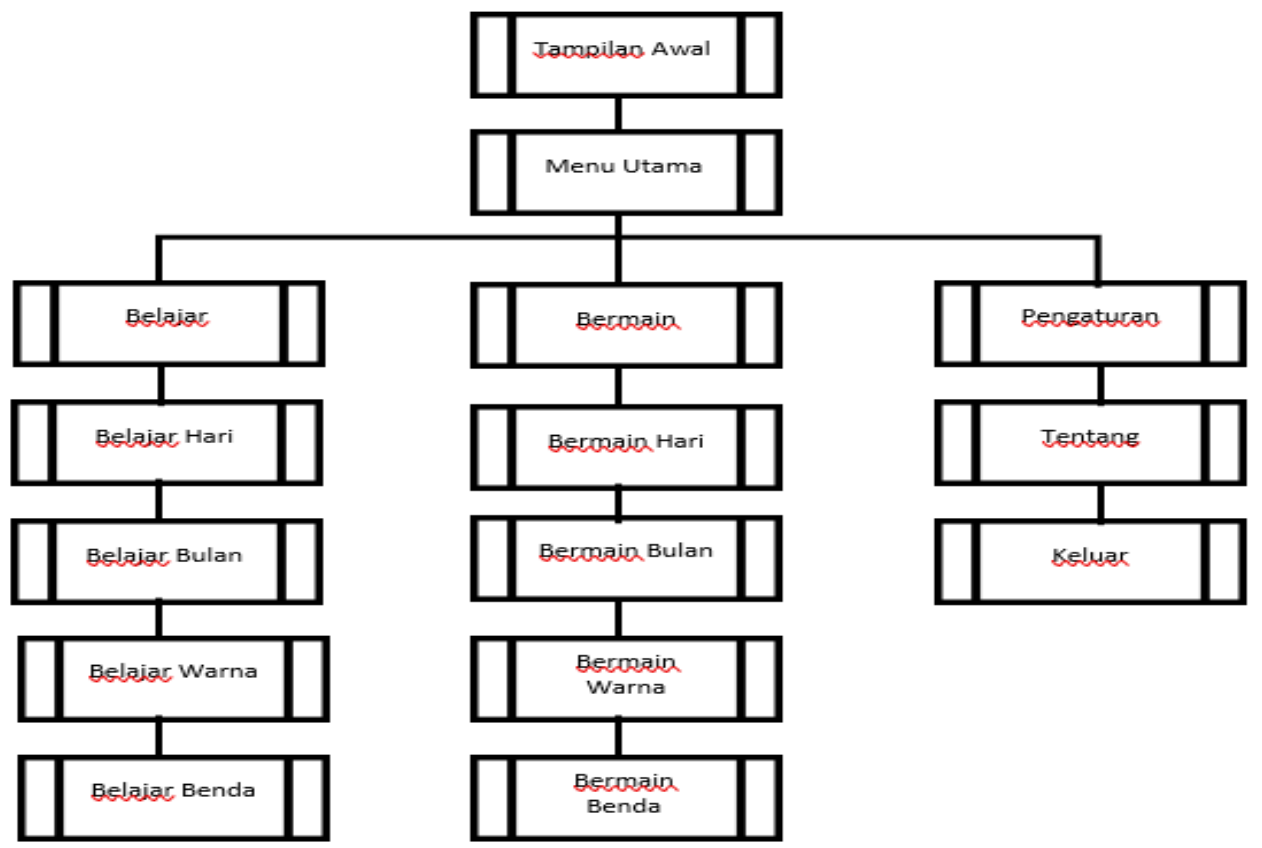

Sumber: (Bismi et al., 2021)

Gambar 5. Diagram HIPO Aplikasi Bahasa Arab 


\section{Pembuatan Aplikasi}

Pada pembuatan aplikasi bahasa arab ini dikarenakan fungsinya yang bersifat pembelajaran, aplikasi ini dibuat tidak terlalu berlebihan sehingga siswa Madrasah Ibtidaiyah mampu mengoprasikan aplikasi ini dengan baik dan mudah. Dan berikut ini adalah tampilan user interface dari aplikasi belajar Bahasa Arab antara lain :

1. Menu Utama

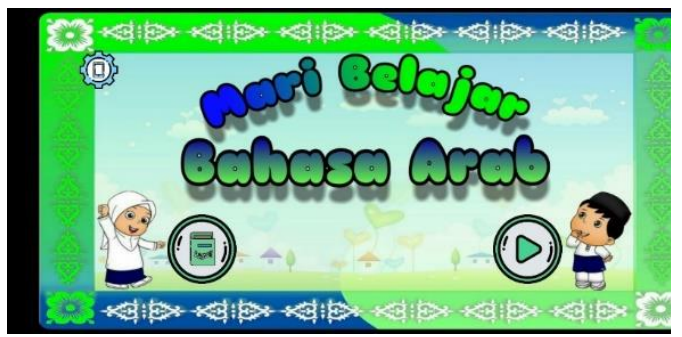

Sumber: (Bismi et al., 2021)

Gambar 6. Tampilan Menu Utama

2. Menu Belajar

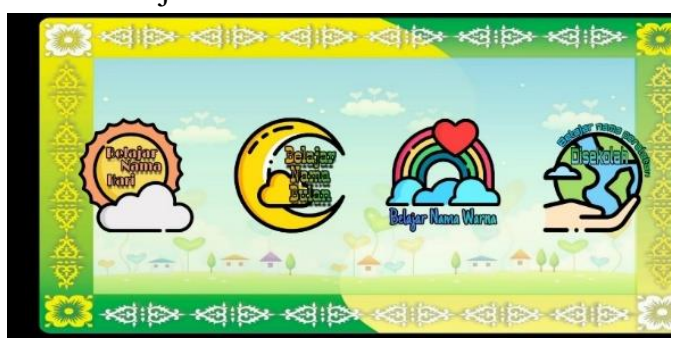

Sumber: (Bismi et al., 2021)

Gambar 7. Tampilan Menu Belajar

3. Halaman Belajar

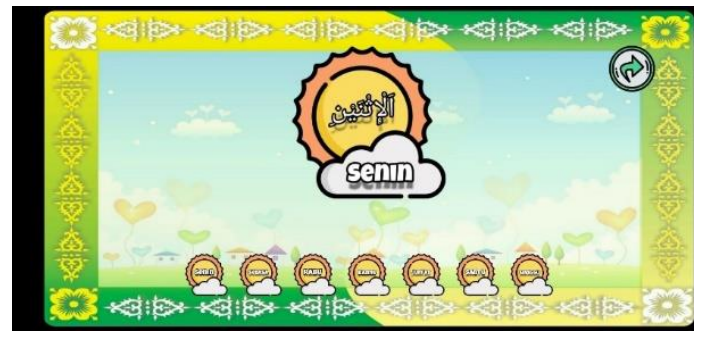

Sumber : (Bismi et al., 2021)

Gambar 8. Tampilan Belajar Nama-Nama Hari

\section{Menu Bermain}

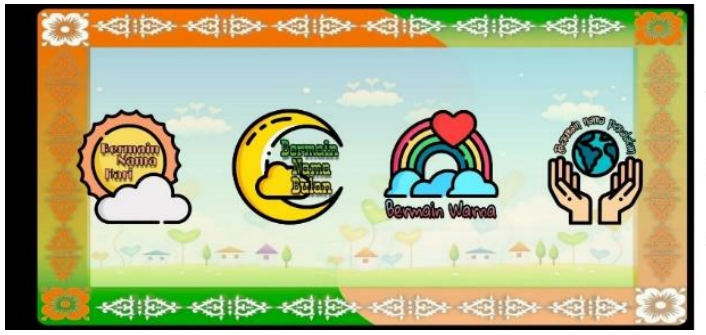

Sumber : (Bismi et al., 2021)

Gambar 9. Tampilan Menu Bermain

5. Halaman Bermain

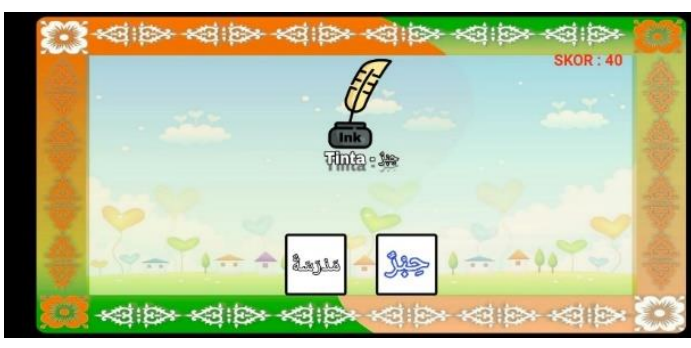

Sumber : (Bismi et al., 2021)

Gambar 10. Tampilan Bermain Benda

6. Menu Pengaturan

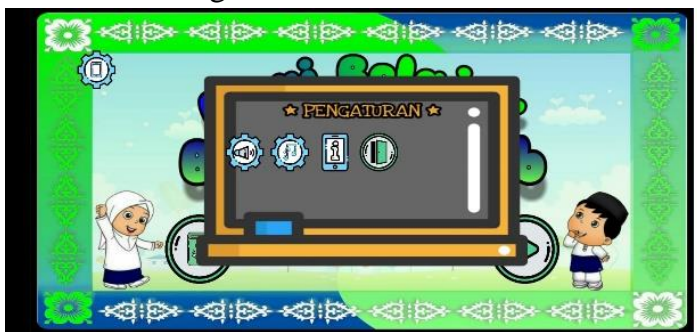

Sumber : (Bismi et al., 2021)

Gambar 11. Tampilan menu Pengaturan 


\section{KESIMPULAN}

Dari pembahasan yang sudah dijabarkan penulis mengenai Aplikasi Pembelajaran Bahasa Arab berbasis Android di penelitian ini, penulis mengambil kesimpulan bahwa Aplikasi Pembelajaran Bahasa Arab berbasis Android ini dapat dijalankan pada telepon pintar (Smartphone) yang compatible denga Android OS dengan spesifikasi minimal OS Lollipop. Pembuatan aplikasi ini bertujuan sebagai media pembelajaran kepada murid sekolah dasar dalam mengenal dan mempelajari Bahasa Arab untuk pemula. Adapun Materi pembelajaran Bahasa Arab yang terdapat di dalam aplikasi ini adalah berupa pengenalan-pengenalan nama hari,bulan,warna dan benda dalam bahasa arab maupun bahasa Indonesia yang mudah dipahami oleh anak-anak.

Kemudian agar meningkatkan antusias pengguna maka terdapat menu bermain atau latihan soal yang digunakan untuk mengasah kemampuan mengingat anak-anak setelah memelajarinya di menu belajar dan pengguna dapat dengan mudah mengevaluasi hasil pembelajarannya, karena terdapat nilai atau skor saat mengerjakan latihan soal.

\section{REFERENSI}

Aditama, D., Rosyid, H., \& Fahriani, N. (2018). Aplikasi Pembelajaran Alfanumerik Untuk Anak Usia PraSekolah Berbasis Android Menggunakan Metode Tesseract-Ocr. Journal of Computer Science and Informatics Engineering (J-Cosine), 2(1), 70-76. https://doi.org/10.29303/jcosine.v2i1.128

Bismi, W., Maysaroh, M., \& Asra, T. (2020). Rancang Bangun Aplikasi Pembelajaran Mahfudzot Untuk Pondok Pesantren Berbasis Android Menggunakan Metode Extreme Programming. Semnas Ristek (Seminar Nasional Riset Dan Inovasi Teknologi), 4(1), 15-21.

Bismi, W., Napiah, M., Putra, J. L., \& Shidiq, F. (2021). Rancang Bangun Aplikasi Pembelajaran Bahasa Arab Untuk Siswa Madrasah Ibtidaiyah Berbasis Android.

Dharmawan, E. A., Ginting, S. W., \& Noya, F. (2017). Rancang Bangun Aplikasi Penentu Tarif Dasar Ojek Di Kota Ambon Berbasis Android. Jurnal Simetrik, 7(2), 38-41. https://doi.org/10.31959/JS.V7I2.45

Firly, N. (2018). Create Your Own Android Application. Elex Media Komputer.

Juhara, Z. P. (2016). Panduan Lengkap Pemrograman Android (1st ed.). ANDI.

Kurniawan, N. T., \& Katarina, D. (2021). PERANCANGAN APLIKASI EDUKASI PEMBELAJARAN IPS BERBASIS ANDROID PADA KURIKULUM 2013. 1398-1401.

Kusniyati, H., \& Pangondian Sitanggang, N. S. (2016). Aplikasi Edukasi Budaya Toba Samosir Berbasis Android. Jurnal Teknik Informatika, 9(1), 9-18. https://doi.org/10.15408/jti.v9i1.5573

Putra, J. A., \& Agustaf, R. (2019). RANCANG BANGUN VISUALISASI TOURISM GUIDE PROVINSI DAERAH ISTIMEWA YOGYAKARTA. Jurnal Informasi Interaktif, 4(1), (halaman 2).

Rahmawati, E., \& Abdurahman, E. (2019). Pemodelan aplikasi dunia islam mengaji berbasis android. 4(2), 197202.

Ramadhan M, M. Y. (2018). APLIKASI INFORMASI TRANSPORTASI ANGKUTAN UMUM ANTAR KOTA PADA TERMINAL AMPLAS SUMATRA UTARA. Jurnal Sistem Informasi Dan Teknologi (SITECH), $1(2), 1-6$.

Salahudin, Z. (2021). APLIKASI PEMBELAJARAN BAHASA KOREA BERBASIS.

Santoso, S., \& Nurmalina, R. (2017). Perencanaan dan Pengembangan Aplikasi Absensi Mahasiswa Menggunakan Smart Card Guna Pengembangan Kampus Cerdas (Studi Kasus Politeknik Negeri Tanah Laut). Jurnal Integrasi, 9(1), 84-91.

Septian, H., Hidayat, E. W., \& Rahmatulloh, A. (2018). Aplikasi Pengenalan Bahasa Arab dan Inggris untuk AnakAnak Berbasis Android. Jurnal Online Informatika, 2(2), 71. https://doi.org/10.15575/join.v2i2.100

Supardi, ir. Y. (2017). Koleksi Program Tugas Akhir Dan Skripsi dengan Android. Elex Media Komputer. 